\title{
Managing Supernumerary Teeth: A Report of Four Cases
}

\author{
Bindu Kadian ${ }^{1}$, Natasha Saini ${ }^{2}$, Parul Singhal ${ }^{3}$, Ishika Garg ${ }^{4}$, Ritu Namdev ${ }^{5}$
}

\section{Abstract}

A supernumerary tooth represents a tooth that is excess or additional to the natural series. They can be found anywhere in dental arches but often located in maxillary anterior region. The presence of these in oral cavity may lead to certain complications like impaction, delayed or ectopic eruption of adjacent teeth, which may further lead to crowding, midline diastema, and eruption into the floor of the nasal cavity. Therefore, proper management is of utmost importance to avoid these consequences. This article emphasizes the role of early orthodontic treatment in managing complications associated with supernumerary.

Keywords: Early orthodontic, Management, Supernumerary teeth.

Journal of South Asian Association of Pediatric Dentistry (2020): 10.5005/jp-journals-10077-3043

\section{INTRODUCTION}

A supernumerary tooth - the name itself suggests an extra tooth in addition to normal number of teeth present in oral cavity. ${ }^{1}$ Although, they may be found in any region but most commonly appear in maxillary midline region. ${ }^{2}$ They may be found as a single or multiple entity, unilateral or bilateral, and impacted or erupted.

Their pesence is associated with disruptive eruption of permanent teeth in $28-60 \%$ of cases and they are present in $0.8 \%$ of primary dentitions and in $2.1 \%$ of permanent dentitions. ${ }^{3}$ Among sexual prevalence, males (62.2-87\%) are on higher sides than females. ${ }^{4}$ In Caucasian, this range varies in-between $1 \%$ and $3 \% .^{5}$ Chinese $(3.4 \%)^{6}$ have higher prevalence than Japanese $(2.7 \%) .{ }^{7}$

Four types of supernumerary teeth have been reported in the literature: ${ }^{8}$

- Peg-shaped (complete root formation).

- Incisiform or supplemental teeth (normal or smaller in size).

- Tuberculated form (multiple tubercles in anatomic crown).

- Odontome.

As mentioned earlier, their presence is associated with many consequences; one is follicular cyst formation which may lead to significant bone destruction and root resorption of permanent incisors. ${ }^{9,10}$ Therefore, surgical removal is indicated as a preventive measure. It has been found that many developmental disorders are associated with supernumerary teeth like Ellis-Van creveld syndrome, Tricho-Rhino-Phalangeal syndrome, cleft lip and palate, and Gardner's syndrome, etc.

The present article presents the case series with various clinical manifestations and management of impacted supernumerary teeth.

\section{Case Description}

\section{Case 1}

A 12-year-old male patient complained of malaligned teeth. Medical and family history was not remarkable. On inspection, a supernumerary tooth (tuberculate) was present palatal to 11 displacing the later in labial direction (Fig. 1A). However, on analyzing radiographically, an unerupted mesiodens was also seen (Fig. 1B). Treatment was planned to remove both the supernumeraries (Fig. 1C), followed by orthodontic alignment.
${ }^{1-5}$ Department of Pedodontics and Preventive Dentistry, Post Graduate Institute of Dental Sciences, Rohtak, Haryana, India

Corresponding Author: Bindu Kadian, Department of Pedodontics and Preventive Dentistry, Post Graduate Institute of Dental Sciences, Rohtak, Haryana, India, Phone: +91 9466349024, e-mail: Bindu.18july@ gmail.com

How to cite this article: Kadian B, Saini N, Singhal P, et al. Managing Supernumerary Teeth: A Report of Four Cases. J South Asian Assoc Pediatr Dent 2020;3(2):75-79.

Source of support: Nil

Conflict of interest: None

Initially, orthodontic treatment consisted of banding of 16,26 , and bonding rest of teeth with edgewise bracket initiating with $\mathrm{NiTi}$ 0.014 (Fig. 1D). On further follow-ups with subsequent alignment sequence of NiTi were shifted to stainless steel. The treatment goals were achieved in 18 months without any complications (Fig. 1E).

\section{Case 2}

A boy aged 10 years presented with the chief complaint of forwardly placed upper front teeth. Intraoral examination showed mixed dentition with labially placed 21 (Fig. 2A). On palpation, slight bulge was present palatal to 21 . Radiographic examination revealed inverted supernumerary (conical) tooth palatal to 21 (Fig. 2B). After taking the informed consent, surgical extraction of the supernumerary tooth (Fig. 2C) was planned followed by alignment (Fig. 2D) and space closure using upper arch 2 by 4 fixed orthodontic therapy (Fig. 2E). Treatment was completed in 9 months with well-aligned upper arch.

\section{Case 3}

A 9-year-old boy complained of unerupted upper front tooth. Intraoral examination revealed unerupted 12 (Fig. 3A). On radiographic examination, it was found that the supplemental tooth is present distal to the unerupted 12 (Fig. 3B). It was decided to surgically remove the supplemental tooth after taking the informed consent (Fig. 3C) and wait for the spontaneous eruption of 12. Patient was kept on the regular follow-up, and after 12 months, tooth spontaneously erupted into the oral cavity without any sign of complication (Fig. 3D). 

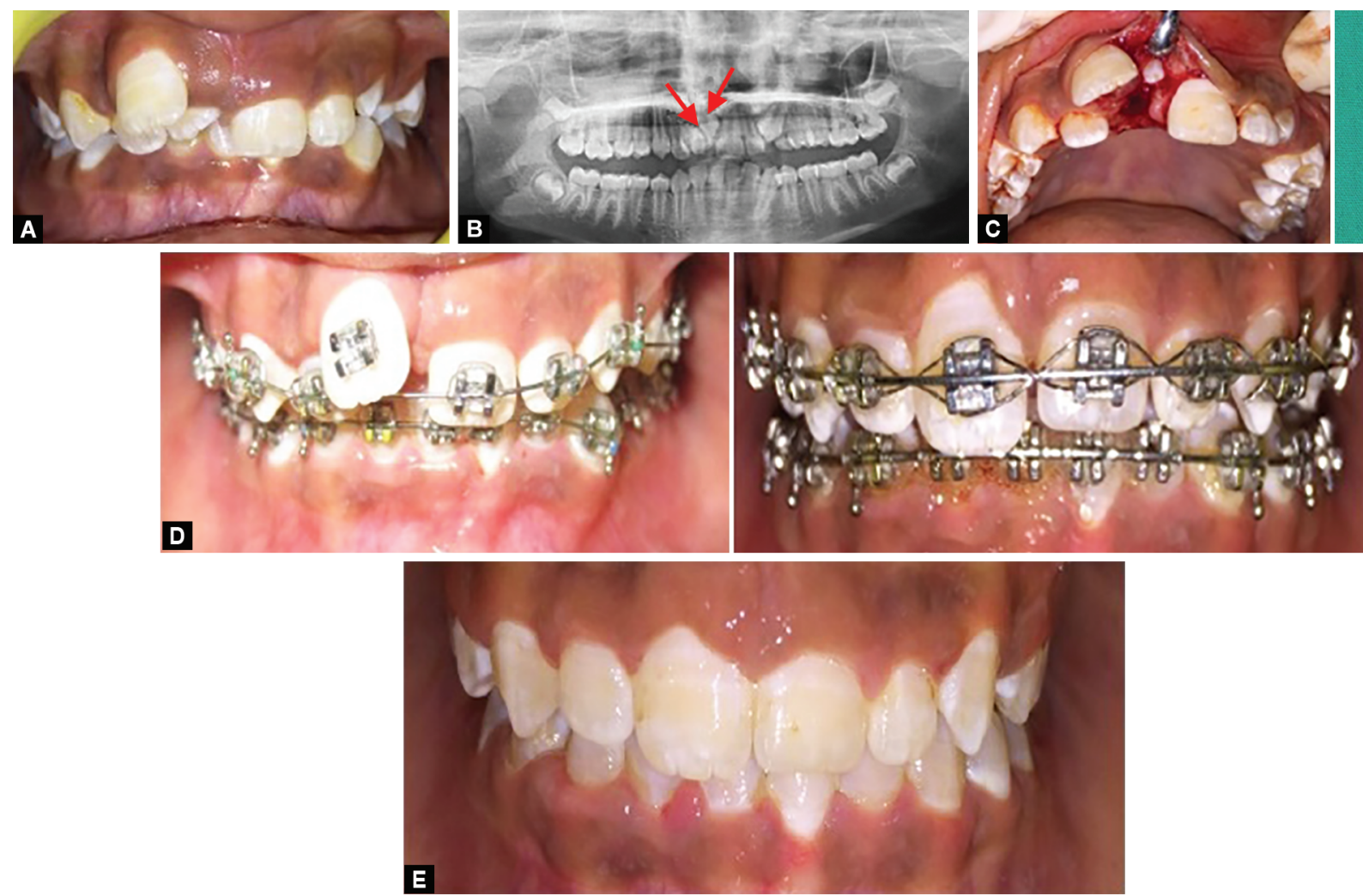

Figs $1 \mathrm{~A}$ to E: (A) Preoperative view with upper anterior supernumerary (Tuberculate type); (B) OPG showing two supernumeraries; (C) Surgical exposure of impacted and extracted supernumerary; (D) Showing full fixed orthodontic treatment; (E) Postoperative view showed well-aligned incisors
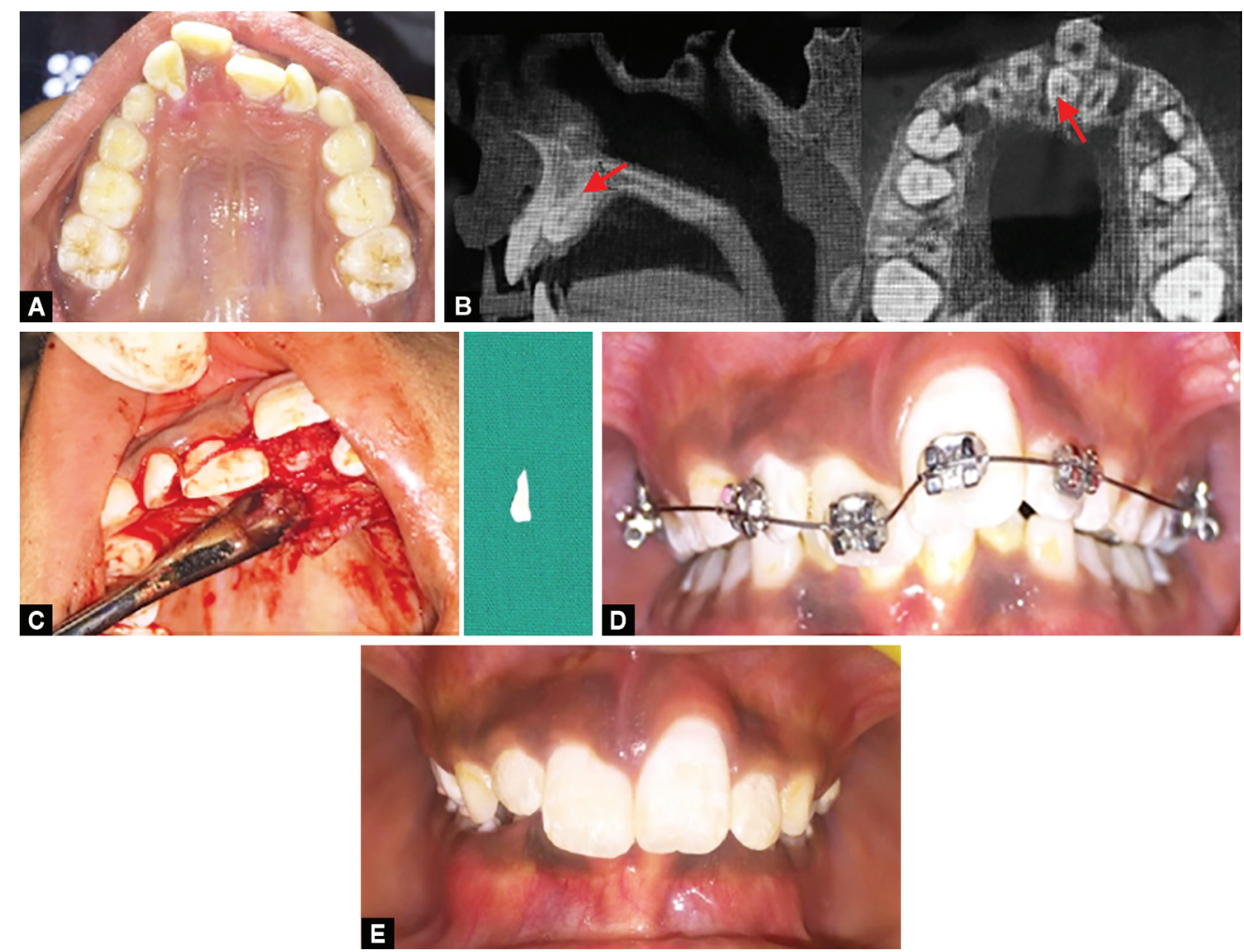

Figs $2 A$ to E: (A) Preoperative view showing palatal bulge of impacted supernumerary and labially displaced 21; (B) CBCT showing supernumerary (conical); (C) Surgical exposure of impacted and extracted supernumerary; (D) $2 \times 4$ fixed orthodontic therapy; (E) Postoperative view 

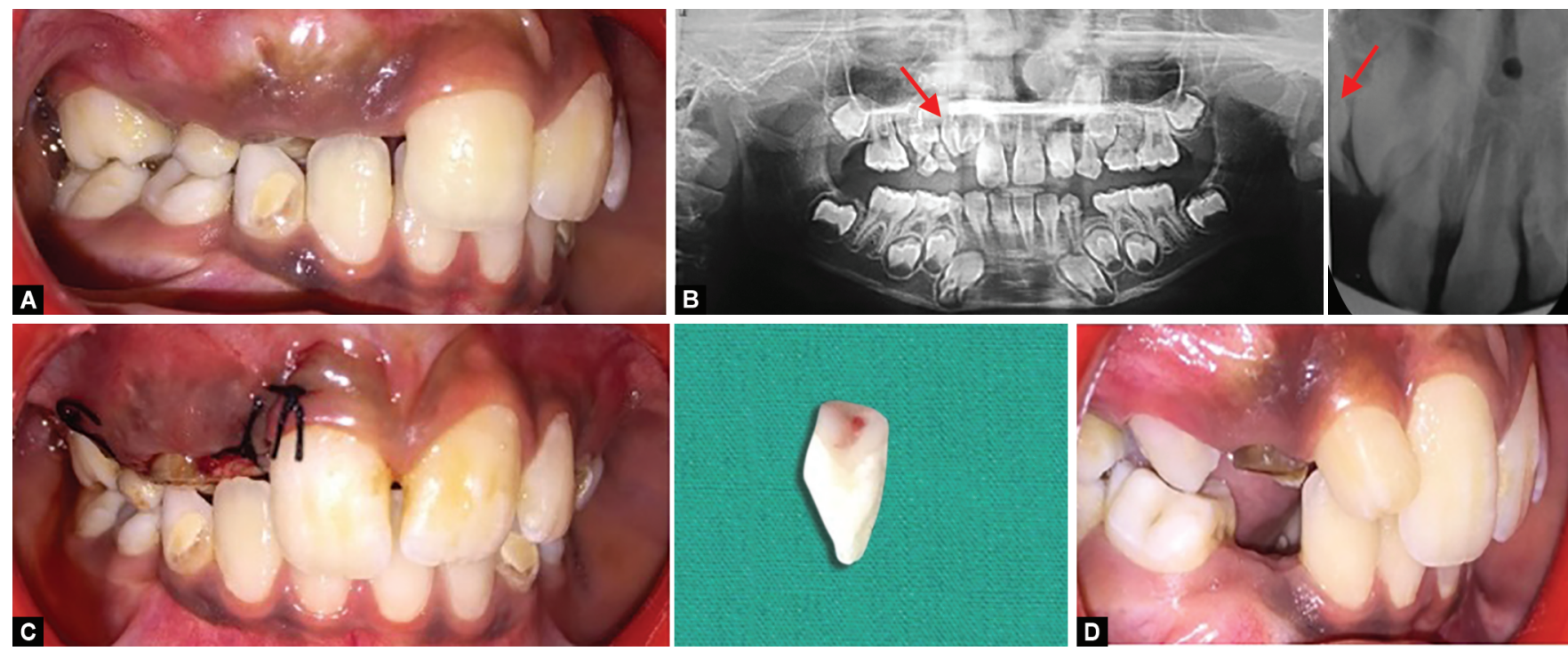

Figs 3 A to D: (A) Preoperative view showing unerupted 12; (B) Radiograph showing supplemental tooth distal to the unerupted 12; (C) Extracted supernumerary; (D) Erupted 12
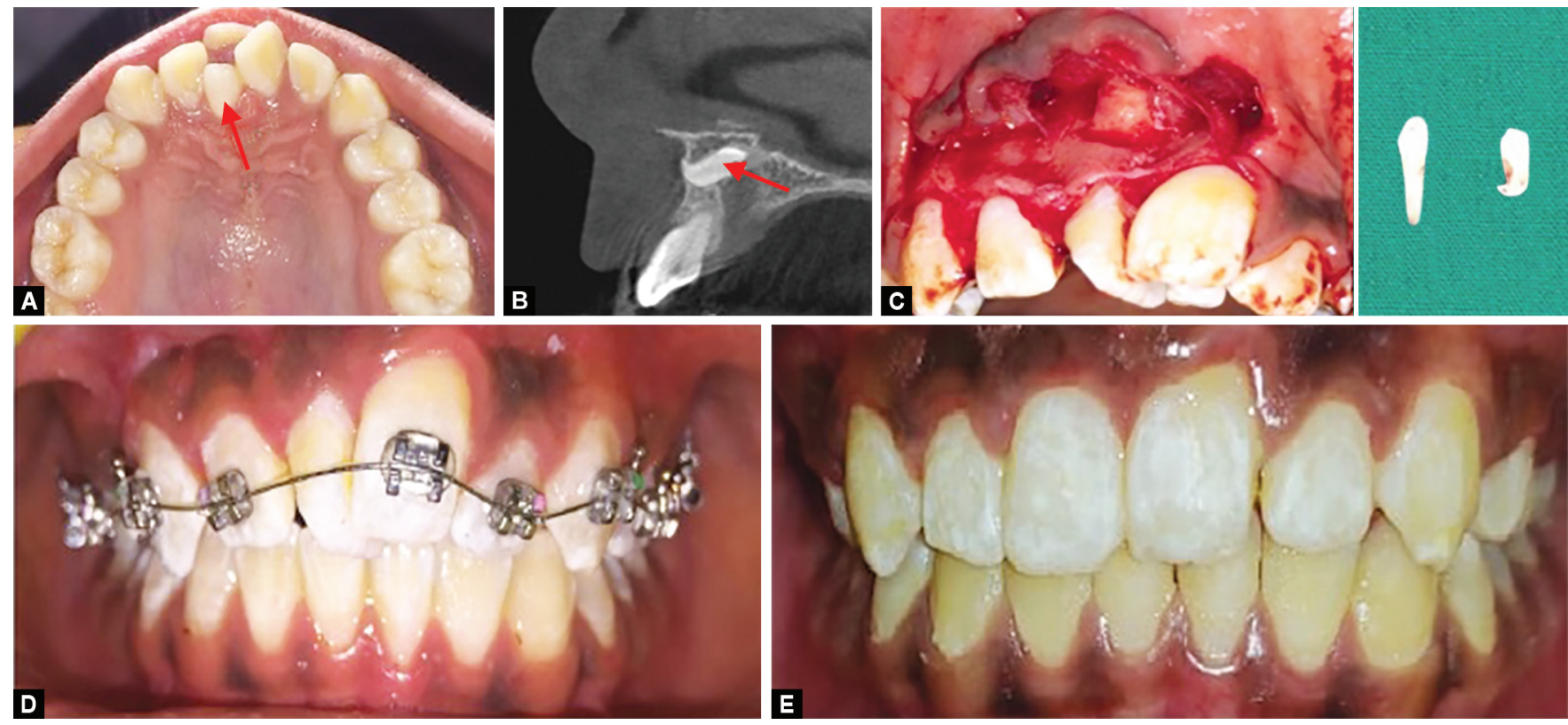

Figs 4A to E: (A) Preoperative view showing mesiodens displacing 21 labially; (B) CBCT showing presence of another impacted supernumerary; (C) Surgical exposure of impacted and extracted supernumerary; (D) Upper full fixed orthodontic treatment; (E) Postoperative view

\section{Case 4}

A young male patient of 12 years presented with malaligned upper front teeth. Medical, dental, and family histories were noncontributory. On intraoral examination, a mesiodens was found which deviated 21 labio-cervically (Fig. 4A). In addition, rotation of 11 was also found. Radiographic examination showed presence of two supernumerary, one is conical supernumerary palatal to 21 and another is inverted apico-palatally to 11 (Fig. 4B). After taking informed consent, both the supernumeraries were surgically extracted (Fig. 4C) subsequent to which upper full arch was orthodontically treated for malalignment (Fig. 4D) and space closure (Fig. 4E). Complete alignment and space closure of upper arch were achieved in 12 months.

\section{Discussion}

Treatment of supernumerary tooth requires a multidisciplinary approach. Before a definitive diagnosis is made, it is important to identify the spatial position of tooth both clinically and radiographically. For accurate location and association of supernumerary tooth with important anatomical landmarks or other anomalies, readiographs play very crucial role. On the basis of both clinical and radiographic findings required, treatment 
plan for the management of supernumerary tooth should be formulated.

Multiple supernumerary teeth (in the absence of any syndrome) may be found mostly in the anterior maxilla (Yusof et al..) ${ }^{11}$ and are mostly observed in an inverted position (Tay et al.). ${ }^{12}$ In the present cases 1, 2, and 4, complication associated with the supernumerary teeth was malalignment, which became the reason for the esthetic concern to the patient. So, extraction followed by orthodontic alignment was performed.

Di Biase ${ }^{13}$ observed that after extraction of supernumerary tooth, $75 \%$ of incisors erupted spontaneously, on an average within 18 months, if the erupting tooth was not pushed too far and if sufficient space was available. As in case 3, supernumerary prevented the eruption of 12 , which was erupted after extraction of it.

However, Ashkenazi et al. ${ }^{14}$ enumerated certain parameters which governed the spontaneous eruption of an impacted tooth after extraction of a supernumerary tooth or odontoma, which included distance between the apex at actual and estimated positions of the impacted tooth, long axis angle of impacted tooth relative to the midpalatal suture, nolla stage of root formation of the supernumerary tooth, total number of supernumerary teeth (3 or more), time from first surgery to the eruption time of the impacted teeth, and amount of space loss. Treatment of supernumerary teeth involves various opinions especially regarding the optimal timings of removal. ${ }^{15}$ Some suggest removal immediately after diagnosis to prevent abnormal eruption pattern, eruption potential, and loss of space, etc., while others favor deferring surgery until roots of the neighboring incisors are completely formed because it may damage, devitalize, or malform the adjacent teeth and might be futile if complications will not develop in the future. ${ }^{15}$ However, $\mathrm{Koch}^{16}$ stated that immediate removal of supernumeraries is not necessary if no pathology is present. Erupted supernumeraries should be preferentially extracted except in cases where the supernumerary teeth need to be retained. Supernumerary can either be removed alone or with immediate orthodontic traction of unerupted tooth. Gomes et al. ${ }^{17}$ verified that the preferred treatment was surgery followed by orthodontic therapy $(62.0 \%$ cases). Also, the systemic review by Wasserman-Milhem et al. ${ }^{18}$ reported that there was no effect on root length or shape when fixed orthodontic forces were applied on immature teeth. Moreover, apical resorption was proportional to treatment duration irrespective of closure of root apices. In the presented cases, supernumerary teeth resulted in multiple degrees of orthodontic problems like crowding, delayed eruption of permanent incisors, rotation, and displacement resulting in their surgical extraction followed by orthodontic alignment of malaligned permanent teeth. However, Hamilton and Gutmann ${ }^{19}$ observed that apex may close early if orthodontic forces are applied on immature apices. The most common complications related with the supernumerary is owing to interference (eruption and normal alignment of the adjacent teeth) caused by supernumerary may result in diastema, loss of vitality, displacement, impaction, and malocclusion.

The simultaneous presence of supernumerary and diastema formation is rarely observed and occurs in $28.6 \%$ of cases. ${ }^{20}$ Also, the deleterious effect of supernumerary cause by displacement has been observed in $28-63 \%$ of cases, with $82 \%$ of involved teeth displaced in labial direction. ${ }^{17}$ Likewise, altered normal eruption pattern has been reported in $81.1 \%$ of cases ${ }^{21}$ and poses a challenge to the clinician for its proper management.
In the above-discussed cases, supernumerary teeth resulted in esthetic and functional issues, which necessitate their surgical extraction. After removal of supernumerary, it is essential to orthodontically align the malpositioned teeth for better functional and esthetic purposes. Early interceptive treatment during mixed dentition with 2 by 4 or 2 by 6 results in prevention of malocclusion at an earlier stage, improve self-esteem of the patient, reduce cost of treatment, and prevent or minimize the chances of future orthodontic treatment.

\section{Conclusion}

As the prevalence rate increases, complications associated with supernumerary also increases. Therefore, the clinician should thoroughly study the clinical and radiographic presentations of these anomalies to implement appropriate management in order to avoid malocclusion. Interceptive orthodontic treatment during early mixed dentition phase not only help in eruption of impacted tooth but also manage and prevent the developing malocclusion.

\section{References}

1. Garvey MT, Barry HJ, Blake M. Supernumerary teeth - an overview of classification, diagnosis, and management. J Can Dent Assoc 1999;65(11):612-616.

2. Hogstrom A, Anderssson L. Complications related to surgical removal of anterior supernumerary teeth in children. J Dent Child 1987;54(5):341-343.

3. BrookAH.Dental anomalies of number, form and size: their prevalence in British schoolchildren. J Int Assoc Dent Child 1974;5(2):37-53.

4. Rajab LD, Hamdan MA. Supernumerary teeth: review of the literature and a survey of 152 cases. Int J Paediatr Dent 2002;12(4):244-254. DOI: 10.1046/j.1365-263X.2002.00366.x.

5. Cherrik HM. Radiology in the diagnosis of oral pathology in children. Pediatr Dent 1982;3:424.

6. Niswander JD, Sujaku C. Congenital anomalies of teeth in Japanese children. Am J Phys Anthropol 1963;21(4):569-574.

7. Davis PJ. Hypodontia and hyperdontia of permanent teeth in Hong Kong school children. Community Dent Oral Epidemol 1987;15(4):218-220. DOI: 10.1111/j.1600-0528.1987.tb00524.x.

8. Howard RD. The unerupted incisor. A study of the postoperative history of incisors delayed in their eruption by supernumerary teeth. Dent Pract 1967;17(9):332-342.

9. Hattab FN, Yassin OM, Rawashdeh MA. Supernumerary teeth: report of three cases and review of the literature. J Dent Child 1994;61(5):382-393.

10. Solares R. The complications of late diagnosis of anterior supernumerary teeth: case report. J Dent Child 1990;57(3): 209-211.

11. Yusof WZ. Non-syndrome multiple supernumerary teeth: literature review. J Can Dent Assoc 1990;56(2):147-149.

12. Tay F, Pang A, Yuen S. Unerupted maxillary anterior supernumerary teeth: report of 204 cases. ASDC J Dent Child 1984;51(4):289-294.

13. Di Biase DD. The effects of variations in tooth morphology and position on eruption. Dent Pract Dent Rec 1971;22(3):95-108.

14. Ashkenazi M, Greenberg BP, Chodik G, et al. Postoperative prognosis of unerupted teeth after removal of supernumerary teeth or odontomas. Am J Orthod Dentofacial Orthop 2007;131(5):614-619. DOI: 10.1016/j.ajodo.2005.09.032.

15. Mason C, Azam N, Holt RD, et al. A retrospective study of unerupted maxillary incisors associated with supernumerary teeth. $\mathrm{Br} \mathrm{J}$ Oral Maxillofac Surg 2000;38(1):62-65. DOI: 10.1054/bjom.1999.0210.

16. Koch H, Schwartz O, Klausen B. Indications for surgical removal of supernumerary teeth in the premaxilla. Int J Oral Maxillofac Surg 1986;15(3):273-281. DOI: 10.1016/S0300-9785(86)80085-0. 
17. Gomes CO, Drummond SN, Jham BC, et al. A survey of 460 supernumerary teeth in Brazilian children and adolescents. Int J Paediatr Dent 2008;18(2):98-106. DOI: 10.1111/j.1365-263X. 2007.00862.x.

18. Wasserman-Milhem I, Bravo-Casanova ML, Caraballo-Moreno FA, et al. Orthodontic tooth movement in immature apices: a systematic review. Rev Fac Odontol Univ Antioq 2016;27(2): 367-388.
19. Hamilton RS, Gutmann JL. Endodontic-orthodontic relationships: a review of integrated treatment planning challenges. Int Endod J 1999;32(5):343-360. DOI: 10.1046/j.1365-2591.1999.00252.x.

20. Patil S, Pachori Y, Kaswan S, et al. Frequency of mesiodens in the pediatric population in north india: a radiographic study. J Clin Exp Dent 2013;5(5):223-226.

21. Mukhopadhyay S. Mesiodens: a clinical and radiographic study in children. J Indian Soc Pedod Prev Dent 2011;29(1):34-38. 